\title{
Absence of unilateral adnexa associated with asymptomatic adnexal torsion and autoamputation
}

Received: 14 September 2004 / Accepted: 20 December 2004 / Published online: 12 February 2005

(C) Springer-Verlag Berlin / Heidelberg 2005

\begin{abstract}
We present the case of a patient who had a pelvic mobile mass and unilateral absence of unilateral ovary and ipsilateral partial fallopian tube, which may be associated with asymptomatic adnexal torsion. She had had no previous abdominal operations and no history of acute abdominal pain, nausea or vomiting. There are two possible reasons for unilateral absence of adnexa: one is adnexal torsion and the other is congenital malformation.
\end{abstract}

Keywords Unilateral absence of adnexa ·

Autoamputation

\section{Introduction}

Unilateral absence of an ovary and/or uterine tube is an extremely rare finding, occurring in only one in 11,241 women [1]. There are two possible aetiologies: the absence may be congenital or it may be secondary to adnexal torsion [2]. A case of unilateral absence of adnexa and presence of a mobile calcified mass discovered incidentally during laparoscopy is presented. Only three other cases of absence of adnexa in conjunction with a free-floating mass have been reported so far in the literature.

\section{Case report}

A 23-year-old woman, gravida 0 , para 0 , was admitted to our department with oligomenorrhoea and hirsutism.

E. B. Kilicdag $(\bowtie) \cdot$ E. Tarim · T. Bagis · E. Simsek

B. Haydardedeoglu E. Kuscu

Department of Obstetrics and Gynecology,

Faculty of Medicine, Baskent University,

Yurt Mahalle, 229 Sok, Hakan Burak Apt Kat: 2 Daire: 4,

Seyhan, Adana, Turkey

E-mail: esrabulgan1972@mynet.com

Tel.: +90-322-4586868

Fax: $+90-322-4592622$
She had used oral contraceptives for the past year. She had had no previous abdominal operations. Her menarche had occurred when she was 13 years of age, and she had irregular periods. Physical examination revealed that her FG score was 11, transabdominal sonographic appearance of the left ovary was polycystic and the right ovary was not visualized. The baseline serum concentrations of FSH $[6.32 \mathrm{mIU} / \mathrm{ml}$; normal values (n.v.): 2$10 \mathrm{mIU} / \mathrm{ml}]$, LH $(9.41 \mathrm{mIU} / \mathrm{ml} ;$ n.v. $2-15 \mathrm{mIU} / \mathrm{ml})$, TSH $\quad(2.04 \mu \mathrm{IU} / 1 ; \quad$ n.v: $0.3-4.0 \mu \mathrm{IU} / \mathrm{l})$, prolactin (471.07 mIU/1; n.v: $25.20-628.53 \mathrm{mIU} / \mathrm{l})$ were normal. Both total testosterone $(0.97 \mathrm{ng} / \mathrm{ml}$; n.v: $0.06-0.82 \mathrm{ng} /$ $\mathrm{ml})$, free testosterone $(3.2 \mathrm{pg} / \mathrm{ml}$; n.v: $1.10-3.10 \mathrm{pg} / \mathrm{ml})$, DHEA-S (3794 ng/ml; n.v: 700-3,500 ng/ml), and 17 OH-progesterone $(1.20 \mathrm{ng} / \mathrm{ml}$; n.v: $0.2-0.5 \mathrm{ng} / \mathrm{ml})$ levels were significantly raised. From these features, we diagnosed polycystic ovarian syndrome. Because of the urinary symptoms, direct urography was performed, and a calcified focus was detected at the pelvis. A CT scan of the abdomen revealed a $25 \times 17-\mathrm{mm}$ mobile intraperitoneal omental calcification in the pelvis and absence of the right ovary. USG and CT revealed no abnormalities of the urinary tract. At laparoscopy, the absence of twothirds of the distal part of the right fallopian tube and ovary was noted. The patient had a normal uterus with normal round ligaments and normal left adnexa (Fig. 1). In the right ovarian fossa, a $2 \times 2 \times 0.5-\mathrm{cm}$ mobile calcified mass was detected (Fig. 2). Pathological examination of the mass demonstrated a calcified fibrous mass without any evidence of an ovary.

\section{Discussion}

We describe the unilateral absence of the ovary and partial absence of the ipsilateral fallopian tube. We did not find any other anatomical malformation in this patient. Absence of one or both uterine tubes and ovaries is a finding that has rarely been described. Mylonas et al. [3] recently reported three cases of unilateral ovarian agenesis and reviewed the literature. In total, 13 studies 


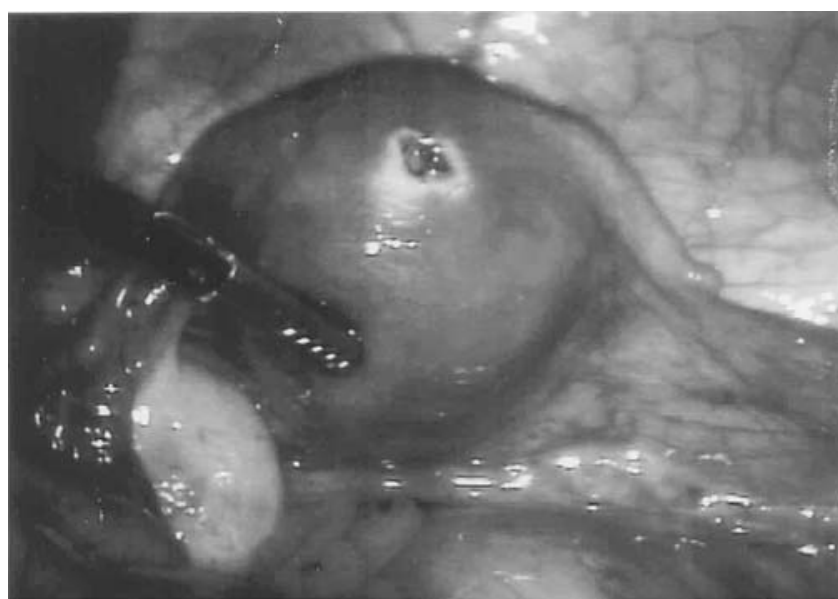

Fig. 1 Laparoscopy revealed a normal uterus, with normal round ligaments and normal left adnexa, but absent right ovary and distal two-thirds part of the tube

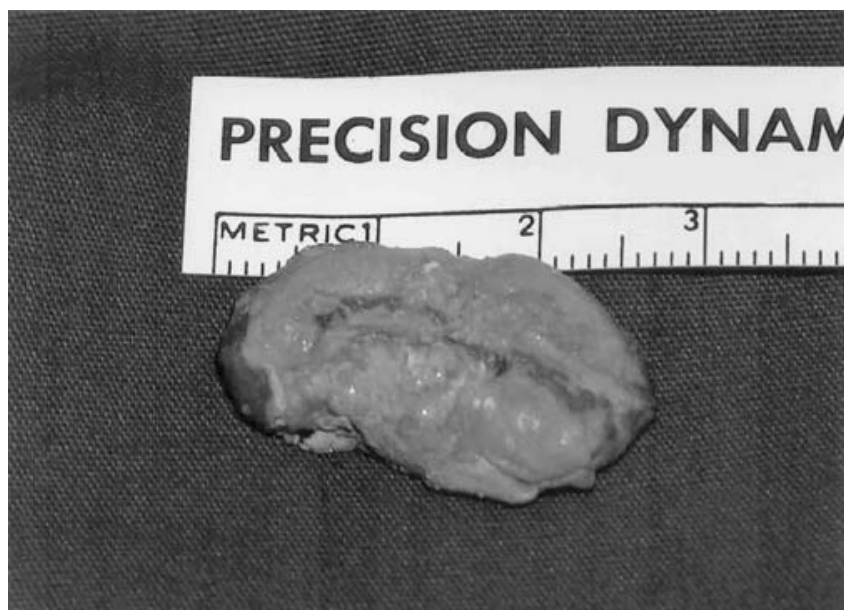

Fig. 2 The $2 \times 2 \times 0.5-\mathrm{cm}$ calcified mass that was detected in the right fossa ovarica

and 19 cases were reported. There are two possible aetiologies. The first involves an asymptomatic torsion of one or both adnexa during adult life or childhood, or even before birth [4]. Alternatively, the absence may be congenital, due to either a defect in the development of the entire mullerian and mesonephric systems on one side, or to a defect localized to the region of the genital ridge and the caudal part of the mullerian duct [2]. Partial or total unilateral defects of a paramesonephric duct are more common than aplasia of both ducts [5]. However, because of the close embryologic association between the genital and urinary tracts, one would expect to find a unicornuate uterus and one ectopic or rudimentary kidney [6]. So, in the case of isolated absence of a tube or ovary, the hypothesis of a congenital malformation is quite weak. However, some authors have suggested that an inadequate blood supply during the descent into the pelvis of the caudal part of the paramesonephric duct might feasibly lead to incomplete tube development [5].

The lack of any other anatomic malformation, and the presence of a mobile mass in the pelvis, suggested that in this case the possible aetiopathogenic cause of the absence of a unilateral adnexa was adnexial torsion. However, the patient did not recall a past history of significant acute abdominal pain, nausea and vomiting, which would suggest an adnexal torsion. It was suggested that torsion could probably have taken place through foetal life [7] or asymptomatic adnexal torsion leading to infarction and autoamputation [8]. A review of the literature revealed three cases of absence of one adnexa in conjunction with a free-floating mass that could be identified as an ovary [8-10]. However, the hypothesis of a congenital defect cannot be excluded.

The aetiology of absent adnexa in most cases is uncertain. Our case supports the adnexal torsion hypothesis.

\section{References}

1. Sivanesaratnam V (1986) Unexplained unilateral absence of ovary and fallopian tube. Eur J Obstet Gynecol Reprod Biol 22:103-105

2. Eustace DL (1992) Congenital absence of fallopian tube and ovary. Eur J Obstet Gynecol Reprod Biol 46:157-159

3. Mylonas I, Hansch S, Markmann S, Bolz M, Friese K (2003) Unilateral ovarian agenesis: report of three cases and review of the literature. Arch Gynecol Obstet 268:57-60

4. Katz VL, McCoy MC, Kuller JA, Hansen WF, Watson WJ (1996) Fetal ovarian torsion appearing as a solid abdominal mass. J Perinatol 16:302-304

5. Paternoster DM, Costantini W, Uglietti A, Vasile C, Bocconi L (1998) Congenital or torsion-induced absence of Fallopian tubes. Two case reports. Minerva Ginecol 50:191-194

6. Mulayim B, Demirbasoglu S, Oral O (2003) Unicornuate uterus and unilateral ovarian agenesis associated with pelvic kidney. Surg Endosc 17:161

7. Dueck A, Poenaru D, Jamieson MA, Kamal IK (2001) Unilateral ovarian agenesis and fallopian tube maldescent. Pediatr Surg Int 17:228-229

8. Olufowobi O, Sorinola O, Afnan M, Papaioannou S, McHugo JM, Sharif K (2002) Spontaneous disappearance of a normal adnexa associated with a contralateral polycystic-appearing ovary. Obstet Gynecol 100:1136-1138

9. Silva PD, Glasser KE, Virata RL (1995) Spontaneously acquired, unilateral absence of the adnexa. A case report. J Reprod Med 40:63-64

10. Sebastian FM, Baker RL, Cowdray D (1973) Asymptomatic infarction of ovary and distal uterine tube. Obstet Gynecol 41:531-532 